\title{
Analysis of structures, functions, and transgenicity of phytopeptides defensin and thionin: a review
}

\author{
Sarfuddin Azmi ${ }^{1^{*}}$ and Mohd Kamil Hussain ${ }^{2^{*}}$ (D)
}

\begin{abstract}
Background: Antimicrobial peptides are very primitive innate defense molecules of almost all organisms, from microbes to mammalians and vascular seed-bearing plants. Antimicrobial peptides of plants categorized into cysteine-rich peptides (CRPs) and others and most of the antimicrobial peptides belong to CRPs group. These peptides reported showing the great extent of protecting property against bacteria, fungi, viruses, insect, nematode, and another kind of microbes. To develop a resistant plant against pathogenic fungi, there have been several studies executed to understand the efficiency of transgenicity of these antimicrobial peptides.

Main text: Apart from the intrinsic property of the higher organism for identifying and activating microbial attack defense device, it also involves innate defense mechanism and molecules. In the current review article, apart from the structural and functional characterization of peptides defensin and thionin, we have attempted to provide a succinct overview of the transgenic development of these defense peptides, that are expressed in a constitutive and or over-expressive manner when biotic and abiotic stress inflicted. Transgenic of different peptides show different competence in plants. Most of the transgenic studies made for defensin and thionin revealed the effective transgenic capacity of these peptides.

Conclusion: There have been several studies reported successful development of transgenic plants based on peptides defensin and thionin and observed diverse level of resistance-conferring potency in different plants against phytopathogenic fungi. But due to long regulatory process, there has not been marketed any antimicrobial peptides based transgenic plants yet. However, success report state that possibly in near future transgenic plants of AMPs would be released with devoid of harmful effect, with good efficiency, reproducibility, stability, and least production cost.
\end{abstract}

Keywords: Antimicrobial peptides, Defensin, Thionin, AMPs transgenic plants

\footnotetext{
*Correspondence: sazmi@psmmc.med.sa; mkhcdri@gmail.com

'Molecular Microbiology Biology Division, Scientific Research Centre (SRC),

Prince Sultan Military Medical City (PSMMC), Sulaimaniyah, Riyadh 11159, Kingdom of Saudi Arabia

${ }^{2}$ Department of Chemistry, Govt. Raza P.G. College, Rampur, Uttar Pradesh 244901, India
} 


\section{Background}

There are various mechanisms by which virtually all species, including microorganisms, attempt to protect themselves against dreadful attacks. Unicellular organisms (prokaryote and eukaryote) use a restriction enzyme system of nucleic acid along with secondary metabolite and proteins/peptides to resist the attack of other microbial cells in the same niche. In higher organisms, multilevel system of innate to adaptive immune exercised in defending against pathogens attack [13, 21, 99]. For instance, in higher vertebrate like mammals utilize various kinds of TLR (toll-like receptor) and NOD-TLR (nucleotide-binding oligomerization domain-TLR), which recognize microbes/pathogen-associated molecular pattern (M/PAMP) and induce various signaling pathway of inflammation and production of different kind of defense protein and peptides $[37,57,88]$. In the adaptive immune response, the mammalian's system produces immunoglobulin or raise specific cells ( $\mathrm{T}$ cells) upon access to specific microbes or any foreign item.

Unlike animals that can move and accommodate themselves in the best suited and available environment, plants remained at the place where they germinated or planted and developed different means of survival against various factors such as adverse environment, insect and nematodes invasion, attack of pathogenic microorganisms, etc. On top of these, there is no systemic circulatory system as like animals, so individual plant cells or tissues produce defense molecules or developed means to recognize the pathogen and put suitable defense measures, from physical barrier like secretion of waxes to avoid their penetration to chemical guard like different secondary metabolites to avoid their growth or colonization. Similar to animals, they utilize analogous of TLR, NOD-TLR; LRR receptor-like kinase (RLK), membrane-anchored LRR-receptor protein (LRP), and NBS-LRR (nucleotide-binding site-leucine rich repeat) to recognize the MAMP. Pathogenesis related gene activated upon exposer of MAMP, like flagellin, methylated DNA fragment, LPS, and its other components, cell wall part peptidoglycan, glucan, chitin and some proteins results from generation and secretion of lytic enzymes, antimicrobial secondary metabolites (phenolics, polyacetylenes, alkaloids, terpenoids, etc.), and various kind of antimicrobial peptides/proteins to inhibit the colonization of microbes (Fig. 1) [8, 43, 49, 85].

Among several defense systems, antimicrobial peptides are produced by almost all organisms, which provide innate immunity against a wide range of microbes. For instance, many of normal floras of the mammalian gut system like, lactobacillus secretes antimicrobial peptide which avoids the colonization of unwanted or pathogenic microbe. In another word, the competition of survival at same niche, several bacteria secrete antimicrobial peptides as defense molecules, Bacteriocin (microcins, colicin, nisin, gramicidin, etc.) to avoid the growth and colonization of other microbes in the same ambiance [5, $23,41,51]$. Likewise, in the response of infection or injury, AMP cecropin secrete in the hemolymph of the pupa of a silkworm. Skin glands of amphibian secrete constitutively temporin, maganin, and several other peptides to fend off the microbial attack [20, 78, 97].

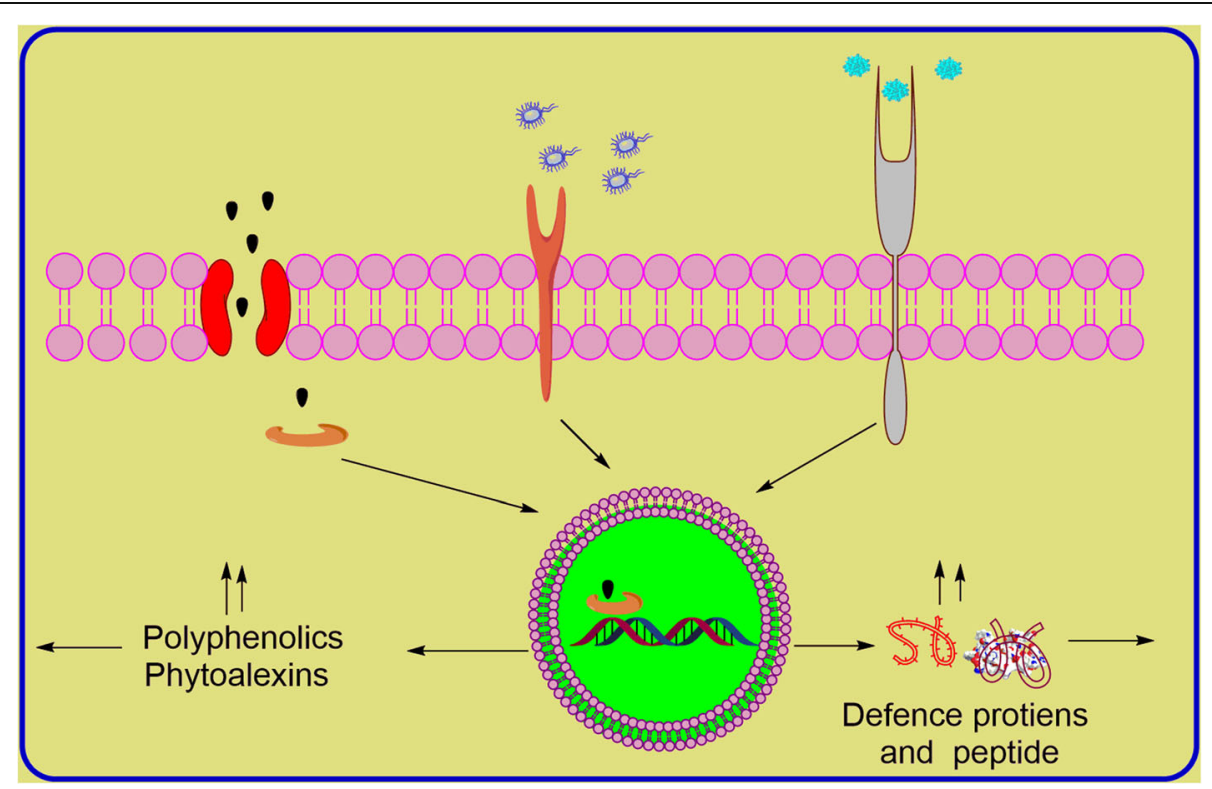

Fig. 1 Schematic representation of constitutively expressing and releasing of various defense molecules and overexpression on biotic and abiotic stress 
Defensins and cathelicidin constitutively as well as overexpress upon ingress of bacteria as innate immune molecules in the mammalian system $[1,30]$. Similarly, plants also secrete various types of antimicrobial peptides in defense measures that kill different pathogenic microbes or stop colonization [31].

Different forms of defensive peptides/proteins have been isolated from various parts of the plants, such as root, stem, leaves, flowers, and seeds. Together with antimicrobial activity against plant pathogens, these peptides demonstrate toxicity to a variety of microbes that show pathogenicity toward animals. Based on the structural motif, disulfide bridges, and sequence homology, plant origin antimicrobial peptide classified into five to eight different class, viz., defensin, thionin, cyclotide; knotting like peptide, lipid transfer protein, heivin-like peptide, snaking, MBP-1 homolog and glycine-rich peptides [31]. In the current review, we have discussed antimicrobial peptides of two classes' defensin and thionin, emphasizing mainly their importance in the development of transgenic development.

\section{Main text}

\subsection{Defensins}

Defensins are a class of small amphipathic antimicrobial cationic peptides with a length of 45 to 54 amino acids and six to eight conserved cysteine residues resulting in three to four disulfide bridges. Based on structural similarities with animal's defensins, antimicrobial peptides of plants are also categorized in this superfamily. The homology in the peptides of animal and plant sources also a direct evolutionary divergence of animals and plant kingdom. The first peptide of this family isolated from wheat and barley grain was $\gamma$-thionin. Due to similarities in preliminary features of $\alpha$-thionin and $\beta$-thionin, the first identified defensin peptide was imprecisely categorized as $\gamma$-thionin [15, 83, 91]. Later on, detail structural characterization revealed that $\gamma$-thionin displays characteristic structural features of animal's defensins, like $\gamma$ core motif GXCX3-9C and other conserved positions of the sequence. Despite having structural similarities and conserved cysteine residues, there are large sequence variations in plant defensins. The variation in a sequence is possibly linked with the diverse and particular biological function of different defensins and differences in the primary structure of plant defensins from an animal, is likely associated with contrasting physiological function of plants and animals $[60,86]$.

Plant defensins are usually monomeric in nature. Most of the peptides of this superfamily were isolated from seeds apart from other parts of plants $[18,56]$. Like other antimicrobial peptides, defensins preferably exhibit antimicrobial activity through perturbation of membrane. Based on the mechanism of action, defensins are divided into two categories, majorly one which mainly damages the integrity of membrane/fungal hyphae and other which inhibit molecular process, like replication/ transcription/translation/other types of machinery. Mechanistic evaluation of defensins suggested that membrane receptor glucosylceramide probably direct interaction and insertion of defensins which lead the morphological damage of fungal cells [19, 27, 34, 74].

In general, there are three methods or models used to describe the mechanism of antimicrobial peptide, viz., (i) carpet model, (ii) barrel stave model, and (iii) toroidal pore model. Briefly, "Carpet model" peptides are electrostatically attracted to the negatively charged phospholipid head groups at numerous sites covering the surface of the membrane in a carpet-like manner. Their accretion on the membrane surface generates tension between the two leaflets of the bilayer, which above a threshold concentration disrupts the bilayer in a detergent-like manner which eventually leads to disintegration/rupture of the membrane $([65,77])$. "Barrel-stave model" peptide helices orient themselves in the membrane in such a manner that the hydrophobic portion of the peptide align with the hydrophobic lipid acyl chains of the core of the bilayer, whereas the hydrophilic portion forms the lining of the interior region of the pore, this topology can be compared with a barrel composed of helical peptides as the staves. In contrast to barrelstave, in "Toroidal-pore model," antimicrobial peptide helices insert themselves perpendicularly into the membrane to relieve the curvature strain caused by peptide binding, in this process, they induce the monolayers to continuously bend causing the water core to be lined by both the inserted peptides and lipid head groups $[24,96]$.

Apart from these models, there is another mechanism explained for defensin. Instead of forming pore directly, defensin interacts with certain phospholipids and facilitates aggregation around, resulting in the permeation of small molecules, ions, and peptides within cells that create reactive oxygen species which eventually stop microbial growth $[6,54,60,94]$. In mechanistic elucidation, liposome pull-down assay and X-ray crystallographic report of defensin $\mathrm{NaD} 1$ of Nicotiana alata revealed that it selectively binds phospholipid phosphatidic acid (PA) (precursor of other phospholipids) and phosphatidylinositol 4,5bisphosphate $\left(\mathrm{NaD1}: \mathrm{PA}: \mathrm{PIP}_{2}\right)$. The specific interaction of $\mathrm{NaD} 1$ with PA and PIP2 triggers oligomerization of defensin-phospholipid which leads to membrane disorder and disruption of microbial cells [63]. Similar to NaD1, HsAFP1 also exhibits membrane permeabilization activity through specific binding and oligomerization with PA and $\mathrm{PIP}_{2}$ [16]. Mechanistic elucidation also revealed that Lys36 and Arg39 of NaD1 and His32 and Arg52 of HsAFP1, as well as phosphate of PA, play a critical role in the selective 
affinity of these defensins toward bacterial membrane [16, 63]. Recently, there has encountered with bi-domain defensin MtDef5, each domain contains 50 amino acids connected through a linker peptide of seven amino acids. Besides, the structural and functional analysis of MtDef5 reveals that replacement of basic amino acids with neutral amino acids of the same core motif removes phospholipid oligomerization properties, which eventually inhibited pore formation activity and subsequently decreased antifungal activity [38].

The structural analysis of conserved tertiary structure and orientation of regular pattern, it has noted that there are two evolutionary independent sub-family of defensins (cis and trans). These two subfamilies are very similar in structural and functional aspects but there are differences in disulfide bridge orientation and intercysteine loop length (Fig. 2). Majority of plant, fungal, and invertebrate defensins belong to cis-type defensin, and trans one includes vertebrate and some invertebrate defensins. Usually, defensins are expressed in precursor form, i.e., N-terminal signal domain which directs its processing and secretion out of the cells and C-terminal matured domain. Based on the structure of precursor protein, plant defensins further subdivided into two class, class 1 and class 2 . Most of the plant defenses belong to class 1 , which consists of an endoplasmic signal domain followed by a mature/active domain and a relatively very small class, class 2 defensin, consisting of an extra acidic C-terminal prodomain which is removed during the process of maturation. The extra structure of acidic C-terminal prodomain identified in the defensin $\mathrm{PhD} 1$ and PhD2 of Petunia hybrid, NaD1 of Nicotiana alata, and developing maize kernel defensin ZmESR6, but the function of this structure is not identified yet. However, it has been advocated that acidic C-terminal prodomain implicate in eliminating the harmful impact of the basic part of defensin or play some role in vacuolar targeting. Plant defensins are potent and broad-spectrum antimicrobial in nature and show activity against bacterial, fungal, viruses, and even against cancerous cells also, but a majority of plant defensins studied or reported at the angle of antifungal activity [45, 63, 76, 89, 90].

Defensins express throughout plant growth but upon induction of any kind of environmental stress (biotic or abiotic), expression exponentially increased [17, 75]. There are several features of defensin, which recognize it as great defense molecules, like systemic distribution provide heavy metal tolerance in the plant, insecticidal activities, protein synthesis inhibition, affect ion channel, antitumor activity, interceding abiotic stress, inhibiting digestive enzymes, etc. [3, 31, 59, 93]. In defense activity

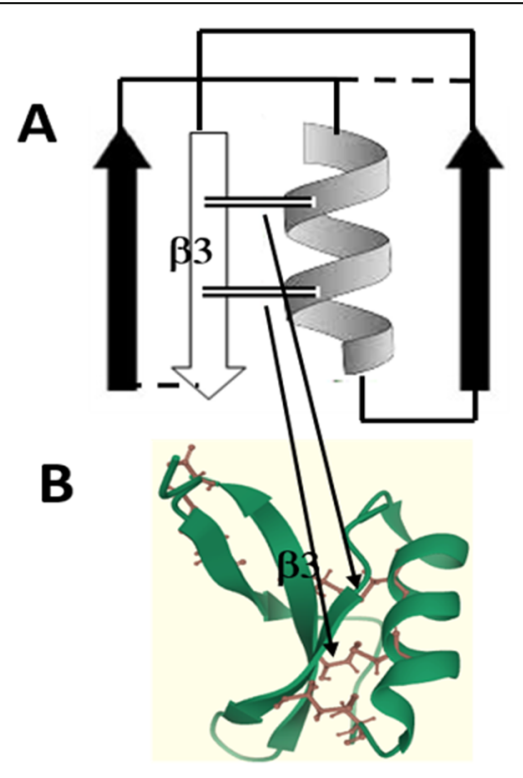

Plant Defensin HsAFP1 (cis-conformation)

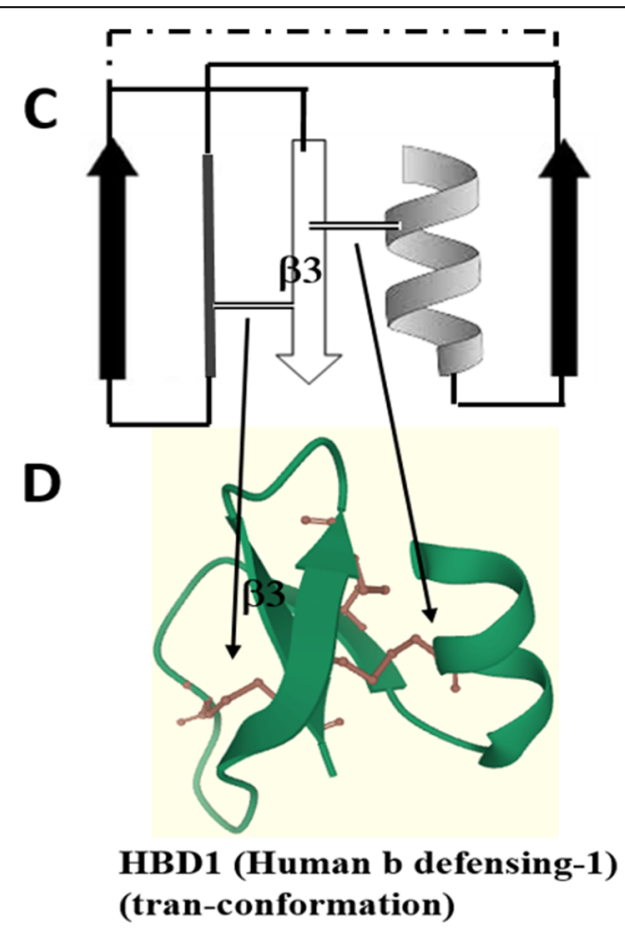

(tran-conformation)

Fig. 2 Representative cis and trans conformation and corresponding tertiary structure of plant defensin HsAFP1 (cis) and human defensin HBD1 (trans). (a and b) Representative and tertiary structure of HsAFP1 (cis) and (c and d). For HBD1 (trans). In cis representative structure of HsAFP1, two consecutive conserved disulfides formed between a-helix and b-3 strand whereas in trans, these two conserved disulfide link form between a-helix and b-3 and b-3 and other secondary structure. --dash line placed between different secondary structure represent non-conserved disulfide bridges 
against insects, some plant defensins exhibit inhibitory activity toward digestive enzyme present in the insect gut like $\alpha$-amylase, trypsin and chymotrypsin, etc., for instance, VrD1 from Vigna radiate, apart from antifungal activity show defense against insect through $\alpha-$ amylase inhibition $[55,59]$. There are some defensinlike, ZmES1-4, play role in reproduction apart from defense $[3,93]$. Plant defensins AhPDF1.1 and AhPDF1.2 were recently identified to show metal $(\mathrm{Zn})$ tolerance in yeast and plant through adaptive behavior of endoplasmic reticulum and another organelle [55]. Additionally, paddy defensin CAL1 plays a key role in the distribution of heavy metal cadmium in leaves and stalk in rice instead. CAL1 chelates heavy metal Cd and prevents entry into the cell compartment; thus, it is transported through xylem sap to the leaves and stalks. Analysis of CAL1gene and its isogenic line NIL (TN1) and isogenic control NIL (CJ06) revealed that the expression of CAL1gene exponentially increases in root and node when it is exposed with $\mathrm{Cd}$. Toward ion channel opening activity, plant defensin $\mathrm{ZmES} 4$ open $\mathrm{K}^{+}$channel Kzml in synergid cells and access of $\mathrm{K}^{+}$ions opened pollen tube in maize [2]. In the action of ion channel blockage, certain defensins, such as AtPDF2.3, physically block potassium channel Kv1.2 and Kv1.6, in a similar manner as previously mentioned for snakes toxin and scorpion [46], defensin MetDef1 interferes with $\mathrm{Ca}^{+2}$ hemostasis by blocking Cav 1.2 channel similar to viral toxin showing toward channel KP4 [45] and recently identified that defensin $\gamma-\mathrm{Z} 1$ and $\gamma-\mathrm{Z} 2$ show $\mathrm{Na}^{+}$ion channel inhibition activity in rat tumor cell [44].
In the last decade, several plant defensins characterized structurally and functionally (Fig. 3). For instance, $\gamma$-hordothionin, it is $5.25 \mathrm{Kd}$ defensin with four disulfide bridge displaying cell-free translation inhibition activity, defensin PhD1 (Petunia hybrid), forty-seven amino acids long peptide, consisting of five disulfide bridge; moreover, this defensin's extra disulfide bridge does not affect the three-dimensional structure 6 . In terms of the sequence, defensins are not very conserved except few amino acid positions, like cysteine, glutamic acid, and glycine. However, in three-dimensional structure, there is conserved $\gamma$-core motif comprises of two antiparallel $\beta$-sheet and with interposed $\beta$-turn region (Fig. $3 \mathrm{~b}$ orange and yellow strand with interposed loop). It is also perceived that $\gamma$-core motif plays an important role for antimicrobial activity but not because of the disulfide loop which stabilizes the structure but due to the abundance of basic amino acids [98].

In the structural and functional studies of Rs-AFP1 and Rs-AFP2 disclose that increasing basic nature amino acids besides existing, through substitution of neutral nature amino acids, increase their antifungal activity $[26,79]$. In another study, it was noticed that the potency of antifungal activity of MtDef directly related to the abundance of basic nature amino acids at $\gamma$-core motif. $\gamma$-core motif of MtDef1 has four basic residues which display potent antifungal activity, but MtDef2 has no antifungal activity in the absence of positively charged amino acids [26, 79]. In another similar kind report, where replacement of $\gamma$-core motif of MtDef1 with MtDef4, turned it potent active

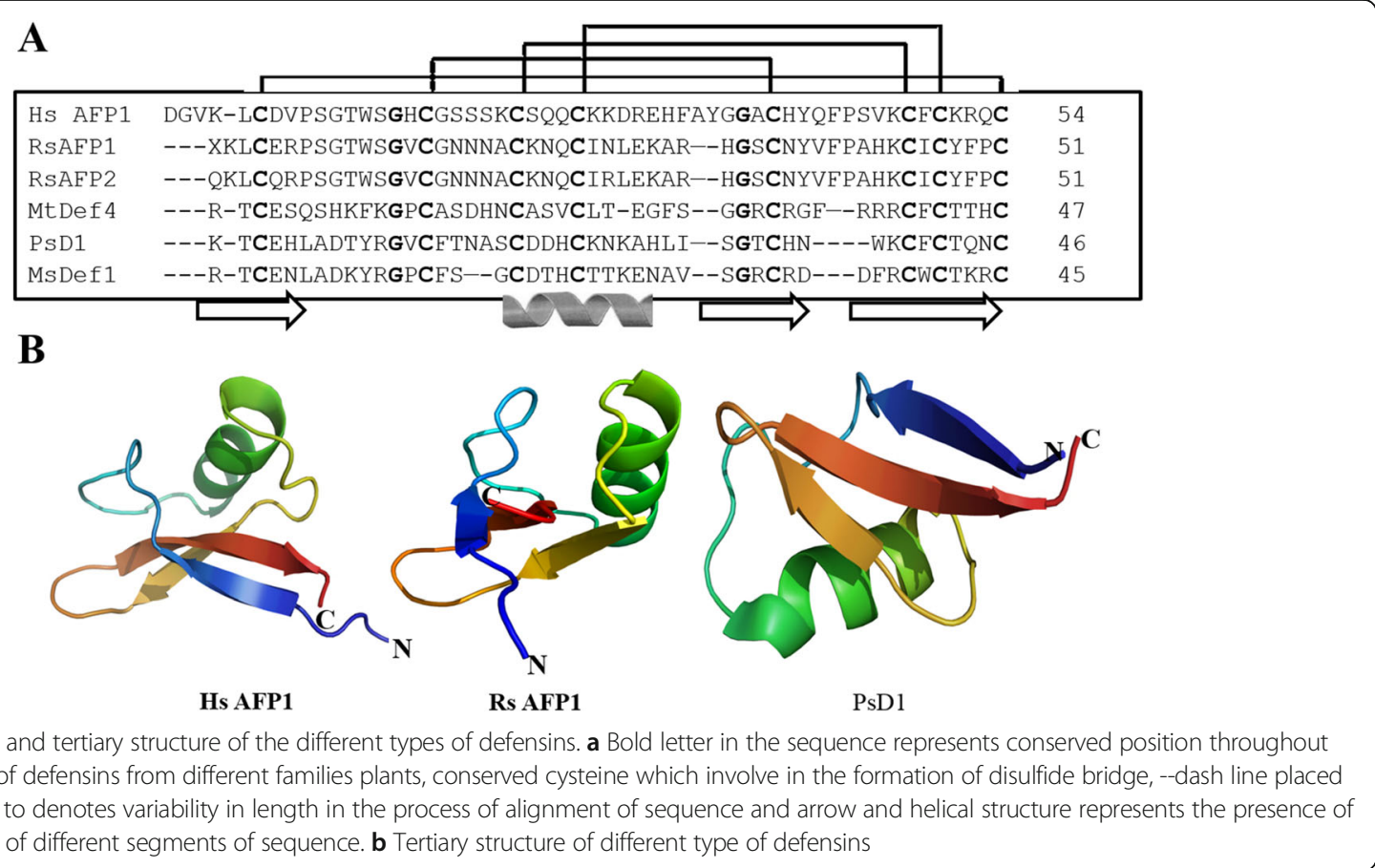


toward phytopathogenic fungal strains, as like MtDef4 [67]. A research report showing novel synthetic peptide similar to $\gamma$-core motif of certain defensin demonstrates inhibitory activity against multiple human pathogenic bacterial strains, such as L. monocytogenes, S. aureus, H. pylori, etc. [64]. Similarly, a recent study of understanding the spectrum of different defensins toward fungal as well as bacterial strains, Andrew et. al., functionally characterized the synthetic $\gamma$-core motif of MsDef1, MtDef4, MtDef5, RsAFP-2, and SoD2. In the investigation, he observed that when the $\gamma$-core is active or inactive against fungal or bacterial strains, its corresponding full-length is effective or inactive accordingly [70].

There are several transgenic plants in the field which confer extra gene of protein having great resistivity against herbicides, insect, and pests. However, there are no single transgenic plants in the market, which confer resistance against pathogenic fungi. But several studies have reported that plant AMP mainly defensins demonstrated successful response to pathogenic microbes in transgenic plants. The first attempt was made in this direction by transforming radish antifungal peptide defensins Rs-AFP2 into tobacco. In this study, the author identified that Rs-AFP2 was overexpressed in foreign plant tobacco and showed significant resistance to Alternaria longipes phytopathogenic fungi [86]. Only a few years later, the same defensin was transformed into an apple by Agrobacterium tumefaciens and in vitro activity study was found to inhibit the spore proliferation of $\mathrm{Fu}$ sarium culmorum by transgenic Rs-AFP2 [39]. Similarly, many more studies have been done through generating transgenic plants of different defensins and reported for significant effectiveness response against different fungi, such as transgenic tomato of Rs-AFP2 (demonstrated efficacy against fungi; F. oxysporum, P. infestans, R. solani, and Alternatia solani) [84], rice (tested against rice blast sheath blight causing fungi $M$. oryzaeand $R$. solani) [46], mustard defensin $\mathrm{BjD}$ transgenic tobacco (tested against F. moniliforme and P. parasitica), etc. [92]. Defensins mainly know for antifungal activity and study of the development of transgenic plant have also done mainly against phytopathogenic fungi. Recently, identification of broad-spectrum nature and great potency of MtDef4 and MtDef5 against a wide range of fungal as well as bacterial strains suggest that development of transgenic plant of these peptides would be very fruitful. Though, the question arises why are defensin transgenics which can defend against pathogenic fungi and bacteria not yet on the market? The answer to this question is any drug or medication or genetically modified organism cannot release on the market a prior comprehensive evaluation of its pro and cone against consumers (animals and humans), environmental risk, effectiveness, reproducibility, stability, and field response by the appointed regulatory authority. Nonetheless, the findings suggest that transgenic plant of defensin will be triumphed in the market soon.

\subsection{Thionins}

The first antimicrobial peptide identified and isolated from the plant was thionin. The name thionins represent a family of homologous peptides, for instance, purothionine, derived from wheat seeds and homologous of this from various sources like vascotoxicins (from the leaves and stem of Viscum album), phoratoxins (from the leaves of Phoradendron tomentosum), ligatoxins A (Phoradendron liga), etc. [62]. This is class of a small plant defense peptide of approximately $5 \mathrm{Kd}$ with six to eight cysteine which involves in disulfide bridge formation [50]. Apart from direct plant protection, thionins also play several other crucial roles, such as protein body packaging or mobilization in the process of germination or dormancy of seed [28]. It also plays a crucial role in the modification of cell walls of fungal hyphae or acts as a subcellular messenger in signal transduction [4, 61].

Structurally, thionins describe as a basic amphipathic peptide with two antiparallel $\alpha$-helices, one antiparallel $\beta$-sheet of two strands, and three to four disulfide bridges. The conserved secondary structure arranges in a pattern of $\beta 1-\alpha 1-\alpha 2-\beta 2$, which ultimately give tertiary structure similar to the Greek letter $\Gamma$. The longer arm comprises of $\alpha 1$ and $\alpha 2$ and shorter one of $\beta 1$ and $\beta 2$ $[14,35,80,82]$ (Fig. 4). The outer surface of the longer arm contains mainly hydrophobic residues where hydrophilic mostly present on the inner surface, the groove between an alpha-helix and beta-sheet, and over the shorter arm. In the groove between $\alpha$-helix and $\beta$-sheet, there is a conserved residues Tyr13, which likely involve in membrane interaction and leakage of microbial cells [50]. In structure and function relation-shipped study of almost all thionins except crambine, it has been observed that conserved position Lys 1 and Tyr 13 play crucial role in toxicity against fungal and animal cells, and the non-toxic Crambins (type-IV thionins) contain Thr and Phe in place of highly conserved position Lys1 and Tyr13 respectively (Fig. 4a). There has been also reported that iodination of Tyr 13 can abolish the toxicity of thionins $[25,29,81,95]$. Thionin gene comprises of twenty amino acids as a leader sequence and sixty amino acids long C-terminal acidic domain apart from the central active domain of 45-47 amino acids [4]. Leader sequence removes in the process of maturation and production of active AMP $[32,72]$. It is postulated by Carrasco, Vazquez et al. [11] and Bohlmann, Clausen et al. [9].

Formerly, thionins were categorized as $\alpha-/ \beta$-thionins and $\gamma$-thionins. Later on, the structural analysis revealed that that $\gamma$-thionins are very similar to another 


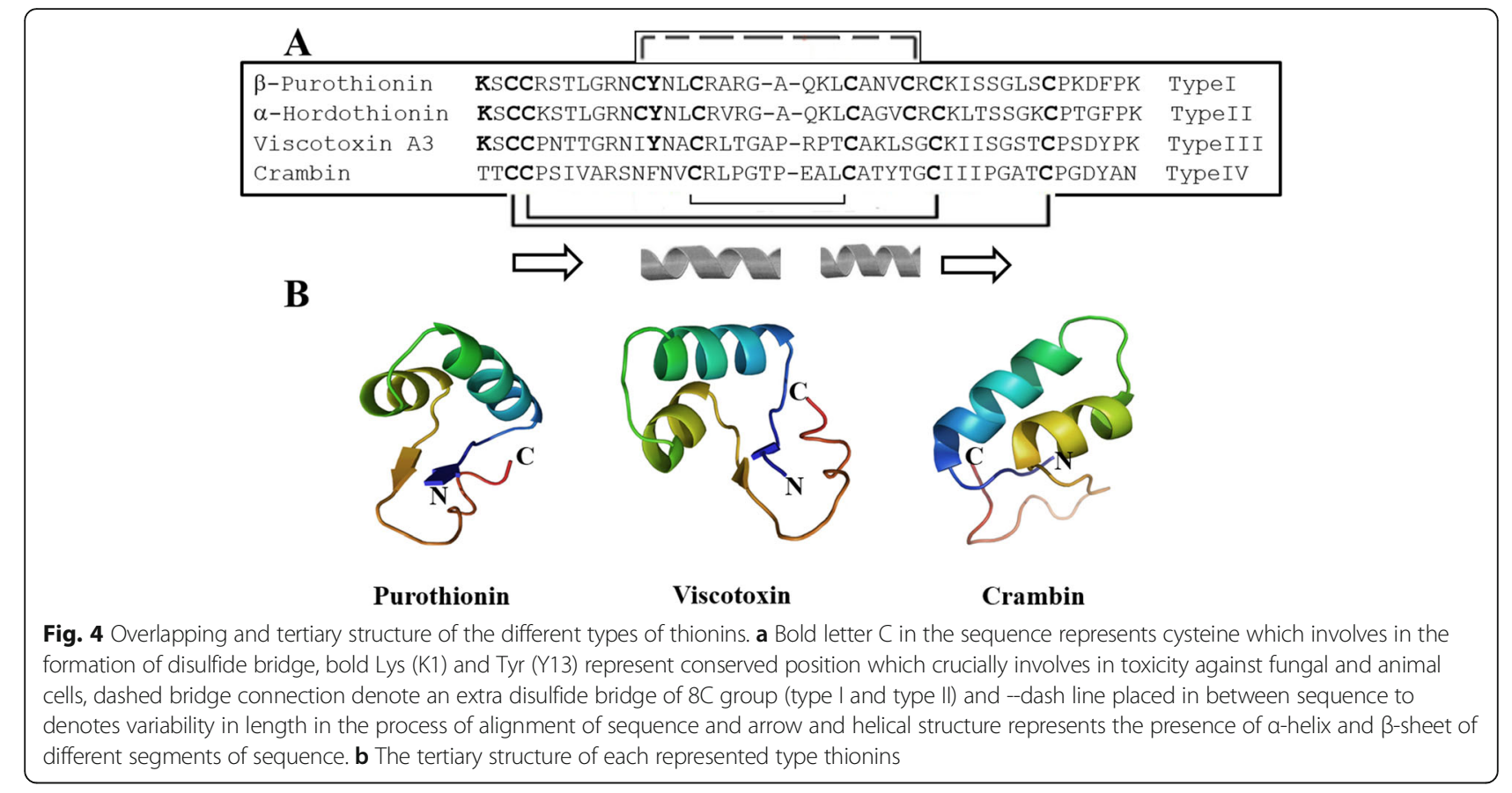

superfamily of peptide defensins and placed in the same [83]. Depending upon the size, numeral of basic residues or net charge, and disulfide bridges, thionins are categorized into five types [80]. Type I, also designate as purothionin, present in endosperm of Poaceae family [21]. It is forty-five amino acids long comprises of four disulfide bridges and highly basic in nature (approximately ten basic residues). Thionintype II ( $\alpha$-Hordothionin and $\beta$-Hordothionin), about 46-47 amino acids long, basic nature and similar to type I possess four disulfide bridges. In contrast to type I, the central disulfide loop comprises a few more amino acids [32, 66]. It is isolated from the leaves of a poisonous plant buffalo nut (family Santalacae) and barely. Viscotoxicin, phoratoxicine, and ligatoxicine have grouped in type III thionins. These are isolated from the stem and leaves of mistletoe species, for example, Viscum album (vascotoxicins), Phoradendron tomentosum (Phoratoxins), and Phoradendron liga (Ligatoxins A). Type III thionins, comprises of 46 amino acids with three disulfide bridges and basicity is very similar to type II $[52,68,69,87]$. Thionin type IV comprises of 46 amino acids with three disulfide bridges and net charge zero at $\mathrm{pH} 7$, for instance, carambine belongs to type IV thionins were isolated from the seed of Abyssinian cabbage. Despite neutral charge and prevalence of hydrophobic residues, it is amphipathic in nature due to the presence of both basic and acidic amino acids [73]. In contrast to the other four categories of thionins, type $\mathrm{V}$ is quite different, such as negatively charged or neutral and a different set of cysteine pairing in disulfide loop formation ([12].
It is believed that thionins exhibit activity through pore forming over pathogen membrane which allows seepage of $\mathrm{Ca}$ and $\mathrm{K}$ ions into or from the cells. As per the previous report, when Neurospora crassa treated with antifungal thionin, Rs-APF2, and Dm-AMP1, induce rapid efflux of $\mathrm{K}$ and uptake $\mathrm{Ca}$, lead shoot up alkalinity of the incubated medium. Similarly, when treated with $\alpha$-hordothionin, apart from the uptake of $\mathrm{Ca}$ and efflux of $\mathrm{K}$ also cause the leakage of $\alpha$ aminobutyric acids which altered the electrical property across the membrane and subsequently lead to the rupture of a lipid bilayer. It is also reported that thionins present in cell walls or space between the membrane and cell walls of some tissues, but accumulated more upon ingression of pathogenic fungal strains [58]. Similarly, other study reported that thionin Asthi1 localized in the cell wall of transgenic rice of the same which accumulate more and invoke resistance against $B$. plantarii and B.glumae upon their inoculation. Not only antimicrobial activity, but some thionins also exert antidote toward toxin, like, Thi2.4 neutralize the toxicity of fungal fruit body lectin (FFBL) released from Fusarium graminearm [4].

In contrast to other plant defense peptides, thionins comprise of relatively more conserved in the sequence of amino acids. Broadly, all five type of thionin categorized into three groups depending on the number of cysteine residue or disulfide loop. Types I and II grouped in one category $8 \mathrm{C}$, where they have 8 cysteine residues, types III and IV are placed in 6C (contain 6 Cysteine), and type $\mathrm{V}$ in another group where two conserved 
disulfide bridges and one novel disulfide loop. In $8 \mathrm{C}$, the pattern of disulfide loops are as CysI-CysVIII, CysIICysVII, CysIII-CysVI, and CysIV-CysV. In these, the first loop connect $\beta 1$ to $C$ terminal coiled part; second, $\beta 1$ to $\beta 2$; third, $\alpha 1$ and loop next to $\alpha 2$; and fourth, $\alpha 1$ to $\alpha 2$. In $6 \mathrm{C}$, the second disulfide bridge CysII-CysVII is not present otherwise all other cysteine pairings remain the same to thionins $8 \mathrm{C}$ (Fig. 4) [53, 95].

Along with the defense of plants, several plant-based antimicrobial peptides also show inhibitory activity toward animal or human pathogen as we discussed above under defensins. In a study, Marta et al. reported that mixture of different thionin ( $\alpha-1, \alpha-2$, and $\beta$ type 1$)$ from wheat $(T$. aestivum) displayed very potent activity against amoebic parasite promastigotes of $L$. donovani compared to defensins and other plant antimicrobial peptides. In the mechanistic elucidation, the author found that thionin dissipates $\mathrm{H} / \mathrm{OH}$ across the membrane which subsequently drops the intracellular level of ATP [7]. Apart from antimicrobial activity, some thionins also exhibit anticancer activities. For instance, thionins Pyrularia pubera (PpTH) exhibit anti-cancer activity against cervical cancer (HeLa) and mouse melanoma (B16) with $\mathrm{IC}_{50}$ approximately $10 \mathrm{nM}$, through $\mathrm{Ca}^{+2}$ mediated activation of phospholipase A2 upon depolarization of plasma membrane [25]. Viscotoxine B2 display antitumor activity against sarcoma with $\mathrm{IC}_{50}$ around $3 \mu \mathrm{M}$ through cell permeabilization [42]. On contrary, viscotoxine A1-3 exhibits a cytotoxic effect toward human lymphocytes through the generation of reactive oxygen species as well as direct membrane damage [10]. Ligatoxin B, show toxic activity toward human adenocarcinoma and Lymphoma cell line (U937GTB) and likely through inhibiting transcription/translation upon direct binding of its DNA binding domain [47]. Thionin phoratoxin (A-F) show toxicity against different kind of cells or tissues, such as phora $\mathrm{A}$ and phora B reported toxic toward rat (at $0.5 \mathrm{mg}^{-1} \mathrm{mg} / \mathrm{kg}$ body weight, through electrical and mechanical damage of papillary muscles cells), phora $\mathrm{C}$, along with anti-tumor activity against different cancerous cells like solid tumor cells (NCI-H69, ACHN) and lymphoma cells (U937GTB), show selective high toxicity toward primary cells of breast cancer among other phoratoxin C-F [40, 71]. Arabidopsis thialiana derived thionin 2.1 exhibits anti-cancer activity against pulmonary adenocarcinoma cell, A549, breast cancer cell MCF-7 and cervical cancer cell HeLa [48]. However, thionin 2.1 also demonstrate inhibitory activity against normal mammary epithelial and endothelial cells of bovine. Together, we can say the non-selective toxic activity of thionins against animals can be exploited to design or modulate for development of novel selective anticancer molecules.

Similar to the defensins, transformation study of thionins have also been done but relatively lesser extent, such as rice plant with transgenic of oat thionin asthi1, afford resistance against B. plantarii and B. gulmae, $\alpha$ Hordothionin expressing transgenic sweet potato described to show resistivity against black rote diseasecausing microbes $C$. fimbriata and transgenic tomato of thionin 2.1, reported to exhibit resistance against several disease-causing microbes [22, 36, 60]. Globally, HLB or citrus greening is vector transmitted one of the most alarming diseases of citrus. Recently, in a study, endogenous thionin of citrus modified and transformed into a variety of citrus-like Carrizo to develop overexpressing transgenic of modified endogenous thionin. The study reported that overexpression of modified thionin develops resistance against citrus canker causing bacteria $\mathrm{X}$ citri as well as a significant reduction in the titter of HBL causative bacteria Candidatus Liberibacterasiaticus (Las) [33]. Together with results suggest that thionins can also be a promising candidate to develop a transgenic plant with potent resistivity against phytopathogenic fungi and bacteria.

\section{Conclusions}

In the logic of development of resistant plants against phytopathogenic fungi, transgenic of AMPs could contribute a very crucial role in agriculture. There have been several transgenic plants in the market which confer extra gene of protein having great resistivity against herbicides, insect, and pests. However, there are no single transgenic plants in the market, which confer resistance against pathogenic fungi. As discussed above that there have been studies reported that the successful development of several transgenic plants of different antimicrobial peptides and observed different level of resistance-conferring potency in every other transgenic plant against phytopathogenic fungi. In the long regulatory process, there has not been marketed any antimicrobial peptides based transgenic plants for phytopathogenic fungi. However, success report state that plausibly in the near future transgenic plants of AMPs would be released with devoid of harmful effect, with good efficiency, reproducibility, stability, and least production cost.

\section{Abbreviations \\ AMPs: Antimicrobial peptides; CRPs: Cysteine-rich peptides; TLR: Toll-like receptor; M/PAMP: Microbes/pathogen-associated molecular pattern; NOD: Nucleotide-binding oligomerization domain; NBS-LRR: Nucleotide- binding site-leucine rich repeat; $\mathrm{PIP}_{2}$ : Phosphatidylinositol 4,5-bisphosphate; MBP1: Mutant p53-Binding Protein 1; Rs-AFP2: Raphanus sativus antifungal peptide 2; PIP2: Phosphatidylinositol 4,5-bisphosphate}

\section{Acknowledgements}

We acknowledge the Scientific Research Center, Prince Sultan Military Medical City for all financial support.

\section{Authors' contributions}

SA (writing draft, review, and edit), MKH (writing draft, review, and edit). The manuscript does not report on or involve the use of any animal or human data or tissue. We confirm that the manuscript has been read and approved for submission by all the named authors. 


\section{Funding}

None.

\section{Availability of data and materials \\ Not applicable.}

\section{Ethics approval and consent to participate}

Not applicable.

\section{Consent for publication}

Not applicable.

\section{Competing interests}

The authors declare that they have no competing interests.

\section{Received: 4 September 2020 Accepted: 21 December 2020} Published online: 14 January 2021

\section{References}

1. Ahmad A, Azmi S, Srivastava RM, Srivastava S, Pandey BK, Saxena R, Bajpai VK, Ghosh JK (2009) Design of nontoxic analogues of cathelicidin-derived bovine antimicrobial peptide BMAP-27: the role of leucine as well as phenylalanine zipper sequences in determining its toxicity. Biochemistry 48(46):10905-10917

2. Allen A, Snyder AK, Preuss M, Nielsen EE, Shah DM, Smith TJ (2008) Plant defensins and virally encoded fungal toxin KP4 inhibit plant root growth. Planta 227(2):331-339

3. Amien S, Kliwer I, Marton ML, Debener T, Geiger D, Becker D, Dresselhaus T (2010) Defensin-like ZmES4 mediates pollen tube burst in maize via opening of the potassium channel KZM1. PLoS Biol 8(6):e1000388

4. Asano T, Miwa A, Maeda K, Kimura M, Nishiuchi T (2013) The secreted antifungal protein thionin 2.4 in Arabidopsis thaliana suppresses the toxicity of a fungal fruit body lectin from Fusarium graminearum. PLoS Pathog 9(8): e1003581

5. Balay DR, Dangeti RV, Kaur K, McMullen LM (2017) Purification of leucocin A for use on wieners to inhibit Listeria monocytogenes in the presence of $s$. poilage organisms. Int J Food Microbiol 255:25-31

6. Barbosa Pelegrini P, Del Sarto RP, Silva ON, Franco OL, Grossi-de-Sa MF (2011) Antibacterial peptides from plants: what they are and how they probably work. Biochem Res Int 250349

7. Berrocal-Lobo M, Molina A, Rodriguez-Palenzuela P, Garcia-Olmedo F, Rivas L (2009) Leishmania donovani: thionins, plant antimicrobial peptides with leishmanicidal activity. Exp Parasitol 122(3):247-249

8. Bianchi ME (2007) DAMPs, PAMPs and alarmins: all we need to know about danger. J Leukoc Biol 81(1):1-5

9. Bohlmann H, Clausen S, Behnke S, Giese H, Hiller C, Reimann-Philipp U, Schrader G, Barkholt V, Apel K (1988) Leaf-specific thionins of barley-a novel class of cell wall proteins toxic to plant-pathogenic fungi and possibly involved in the defence mechanism of plants. Embo J 7(6):1559-1565

10. Bussing A, Stein GM, Wagner M, Wagner B, Schaller G, Pfuller U, Schietzel M (1999) Accidental cell death and generation of reactive oxygen intermediates in human lymphocytes induced by thionins from Viscum album L. Eur J Biochem 262(1):79-87

11. Carrasco L, Vazquez D, Hernandez-Lucas C, Carbonero P, Garcia-Olmedo F (1981) Thionins: plant peptides that modify membrane permeability in cultured mammalian cells. Eur J Biochem 116(1):185-189

12. Castagnaro A, Marana C, Carbonero P, Garcia-Olmedo F (1994) cDNA cloning and nucleotide sequences of alpha 1 and alpha 2 thionins from hexaploid wheat endosperm. Plant Physiol 106(3):1221-1222

13. Choi HW, Klessig DF (2016) DAMPs, MAMPs, and NAMPs in plant innate immunity. BMC Plant Biol 16(1):232

14. Clore GM, Nilges M, Sukumaran DK, Brunger AT, Karplus M, Gronenborn AM (1986) The three-dimensional structure of alpha1-purothionin in solution: combined use of nuclear magnetic resonance, distance geometry and restrained molecular dynamics. Embo J 5(10):2729-2735

15. Colilla FJ, Rocher A, Mendez E (1990) gamma-Purothionins: amino acid sequence of two polypeptides of a new family of thionins from wheat endosperm. FEBS Lett 270(1-2):191-194

16. Cools TL, Vriens K, Struyfs C, Verbandt S, Ramada MHS, Brand GD, Bloch C Jr, Koch B, Traven A, Drijfhout JW, Demuyser L, Kucharikova S, Van Dijck P, Spasic D, Lammertyn J, Cammue BPA, Thevissen K
(2017) The antifungal plant defensin HsAFP1 is a phosphatidic acidinteracting peptide inducing membrane permeabilization. Front Microbiol 8:2295

17. de Beer A, Vivier MA (2011) Four plant defensins from an indigenous South African Brassicaceae species display divergent activities against two test pathogens despite high sequence similarity in the encoding genes. BMC Res Notes 4:459

18. De Lucca AJ, Cleveland TE, Wedge DE (2005) Plant-derived antifungal proteins and peptides. Can J Microbiol 51(12):1001-1014

19. de Paula VS, Razzera G, Barreto-Bergter E, Almeida FC, Valente AP (2011) Portrayal of complex dynamic properties of sugarcane defensin 5 by NMR: multiple motions associated with membrane interaction. Structure 19(1):26-36

20. Duwadi D, Shrestha A, Yilma B, Kozlovski I, Sa-Eed M, Dahal N, Jukosky J (2018) Identification and screening of potent antimicrobial peptides in arthropod genomes. Peptides 103:26-30

21. Egorov TA, Odintsova TI, Pukhalsky VA, Grishin EV (2005) Diversity of wheat anti-microbial peptides. Peptides 26(11):2064-2073

22. Epple P, Apel K, Bohlmann H (1997) Overexpression of an endogenous thionin enhances resistance of Arabidopsis against Fusarium oxysporum. Plant Cell 9(4):509-520

23. Etayash H, Azmi S, Dangeti R, Kaur K (2015) Peptide Bacteriocins--structure activity relationships. Curr Top Med Chem 16(2):220-241

24. Ehrenstein G, Lecar H (1977) Electrically gated ionic channels in lipid bilayers. Q Rev Biophys 10(1):1-34

25. Evans J, Wang YD, Shaw KP, Vernon LP (1989) Cellular responses to Pyrularia thionin are mediated by $\mathrm{Ca} 2+$ influx and phospholipase $\mathrm{A} 2$ activation and are inhibited by thionin tyrosine iodination. Proc Natl Acad Sci U S A 86(15): 5849-5853

26. Fant F, Vranken W, Broekaert W, Borremans F (1998) Determination of the three-dimensional solution structure of Raphanus sativus antifungal protein 1 by $1 \mathrm{H}$ NMR. J Mol Biol 279(1):257-270

27. Farkas A, Maroti G, Durgo H, Gyorgypal Z, Lima RM, Medzihradszky KF, Kereszt A, Mergaert P, Kondorosi E (2014) Medicago truncatula symbiotic peptide NCR247 contributes to bacteroid differentiation through multiple mechanisms. Proc Natl Acad Sci U S A 111(14):5183-5188

28. Florack DE, Stiekema WJ (1994) Thionins: properties, possible biological roles and mechanisms of action. Plant Mol Biol 26(1):25-37

29. Fracki WS, Li D, Owen N, Perry C, Naisbitt GH, Vernon LP (1992) Role of Tyr and Trp in membrane responses of Pyrularia thionin determined by optical and NMR spectra following Tyr iodination and Trp modification. Toxicon 30(11):1427-1440

30. Fruitwala S, El-Naccache DW, Chang TL (2019) Multifaceted immune functions of human defensins and underlying mechanisms. Semin Cell Dev Biol. 88:163-172

31. Garcia-Olmedo F, Molina A, Alamillo JM, Rodriguez-Palenzuela P (1998) Plant defense peptides. Biopolymers 47(6):479-491

32. Gausing K (1987) Thionin genes specifically expressed in barley leaves. Planta 171(2):241-246

33. Hao G, Stover E, Gupta G (2016) Overexpression of a modified plant thionin enhances disease resistance to citrus canker and huanglongbing (HLB). Front Plant Sci 7:1078

34. Hegedus N, Marx F (2013) Antifungal proteins: more than antimicrobials? Fungal Biol Rev 26(4):132-145

35. Hendrickson WA, Teeter MM (1981) Structure of the hydrophobic protein crambin determined directly from the anomalous scattering of sulphur. Nature 290(5802):107-113

36. Holtorf S, Ludwig-Muller J, Apel K, Bohlmann H (1998) High-level expression of a viscotoxin in Arabidopsis thaliana gives enhanced resistance against Plasmodiophora brassicae. Plant Mol Biol 36(5):673-680

37. Imler JL, Hoffmann JA (2001) Toll receptors in innate immunity. Trends Cell Biol 11(7):304-311

38. Islam KT, Velivelli SLS, Berg RH, Oakley B, Shah DM (2017) A novel bi-domain plant defensin MtDef5 with potent broad-spectrum antifungal activity binds to multiple phospholipids and forms oligomers. Sci Rep 7(1):16157

39. Jha S, Chattoo BB (2010) Expression of a plant defensin in rice confers resistance to fungal phytopathogens. Transgenic Res 19(3):373-384

40. Johansson S, Gullbo J, Lindholm P, Ek B, Thunberg E, Samuelsson G, Larsson R, Bohlin L, Claeson P (2003) Small, novel proteins from the mistletoe Phoradendron tomentosum exhibit highly selective cytotoxicity to human breast cancer cells. Cell Mol Life Sci 60(1):165-175 
41. Kaur K, Tarassova O, Dangeti RV, Azmi S, Wishart D, McMullen L, Stiles M (2016) Characterization of a highly potent antimicrobial peptide microcin N from uropathogenic Escherichia coli. FEMS Microbiol Lett 363(11):fnw095

42. Kong JL, Du XB, Fan CX, Xu JF, Zheng XJ (2004) Determination of primary structure of a novel peptide from mistletoe and its antitumor activity. Yao Xue Xue Bao 39(10):813-817

43. Kumar H, Kawai T, Akira S (2011) Pathogen recognition by the innate immune system. Int Rev Immunol 30(1):16-34

44. Kushmerick C, de Souza Castro M, Santos Cruz J, Bloch C Jr, Beirao PS (1998) Functional and structural features of gamma-zeathionins, a new class of sodium channel blockers. FEBS Lett 440(3):302-306

45. Lay FT, Poon S, McKenna JA, Connelly AA, Barbeta BL, McGinness BS, Fox JL, Daly NL, Craik DJ, Heath RL, Anderson MA (2014) The C-terminal propeptide of a plant defensin confers cytoprotective and subcellular targeting functions. BMC Plant Biol 14:41

46. Layer P, Stanghellini V (2014) Review article: Linaclotide for the management of irritable bowel syndrome with constipation. Aliment Pharmacol Ther 39(4):371-384

47. Li SS, Gullbo J, Lindholm P, Larsson R, Thunberg E, Samuelsson G, Bohlin L, Claeson P (2002) Ligatoxin B, a new cytotoxic protein with a novel helixturn-helix DNA-binding domain from the mistletoe Phoradendron liga. Biochem J 366(Pt 2):405-413

48. Loeza-Angeles H, Sagrero-Cisneros E, Lara-Zarate L, Villagomez-Gomez E, Lopez-Meza JE, Ochoa-Zarzosa A (2008) Thionin Thi2.1 from Arabidopsis thaliana expressed in endothelial cells shows antibacterial, antifungal and cytotoxic activity. Biotechnol Lett 30(10):1713-1719

49. Macho AP, Zipfel C (2014) Plant PRRs and the activation of innate immune signaling. Mol Cell 54(2):263-272

50. Majewski J, Stec B (2010) X-ray scattering studies of model lipid membrane interacting with purothionin provide support for a previously proposed mechanism of membrane lysis. Eur Biophys J 39(8):1155-1165

51. Mavridou DAl, Gonzalez D, Kim W, West SA, Foster KR Bacteria use collective behavior to generate diverse combat strategies. Curr Biol 28(3):345-355 e344

52. Mellstrand ST, Samuelsson G (1973) Phoratoxin, a toxic protein from the mistletoe Phoradendron tomentosum subsp. macrophyllum (Loranthaceae). Improvements in the isolation procedure and further studies on the properties. Eur J Biochem 32(1):143-147

53. Milbradt AG, Kerek F, Moroder L, Renner C (2003) Structural characterization of hellethionins from Helleborus purpurascens. Biochemistry 42(8):2404-2411

54. Miteva M, Andersson M, Karshikoff A, Otting G (1999) Molecular electroporation: a unifying concept for the description of membrane pore formation by antibacterial peptides, exemplified with NK-Iysin. FEBS Lett 462(1-2):155-158

55. Mith O, Benhamdi A, Castillo T, Berge M, MacDiarmid CW, Steffen J, Eide DJ, Perrier V, Subileau M, Gosti F, Berthomieu P, Marques L (2015) The antifungal plant defensin AhPDF1.1b is a beneficial factor involved in adaptive response to zinc overload when it is expressed in yeast cells. Microbiologyopen 4(3):409-422

56. Nawrot R, Barylski J, Nowicki G, Broniarczyk J, Buchwald W, GozdzickaJozefiak A (2014) Plant antimicrobial peptides. Folia Microbiol (Praha) 59(3): 181-196

57. Nurnberger T, Brunner F (2002) Innate immunity in plants and animals: emerging parallels between the recognition of general elicitors and pathogen-associated molecular patterns. Curr Opin Plant Biol 5(4):318-324

58. Oard SV (2011) Deciphering a mechanism of membrane permeabilization by alpha-hordothionin peptide. Biochim Biophys Acta 1808(6):1737-1745

59. Oomen RJ, Seveno-Carpentier E, Ricodeau N, Bournaud C, Conejero G, Paris $N$, Berthomieu P, Marques L (2011) Plant defensin AhPDF1.1 is not secreted in leaves but it accumulates in intracellular compartments. New Phytol 192(1):140-150

60. Pelegrini PB, Franco OL (2005) Plant gamma-thionins: novel insights on the mechanism of action of a multi-functional class of defense proteins. Int J Biochem Cell Biol 37(11):2239-2253

61. Pineiro M, Diaz I, Rodriquez-Palenzuela P, Titarenko E, Garcia-Olmedo F (1995) Selective disulphide linkage of plant thionins with other proteins. FEBS Lett 369(2-3):239-242

62. Plattner S, Gruber C, Stadlmann J, Widmann S, Gruber CW, Altmann F, Bohlmann $\mathrm{H}$ (2015) Isolation and characterization of a thionin proproteinprocessing enzyme from barley. J Biol Chem 290(29):18056-18067
63. Poon I, Baxter AA, Lay FT, Mills GD, Adda CG, Payne JA, Phan TK, Ryan GF, White JA, Veneer PK, van der Weerden NL, Anderson MA, Kvansakul M, Hulett MD (2014) Phosphoinositide-mediated oligomerization of a defensin induces cell lysis. Elife 3:e01808

64. Rigano MM, Romanelli A, Fulgione A, Nocerino N, D'Agostino N, Avitabile C, Frusciante L, Barone A, Capuano F, Capparelli R (2012) A novel synthetic peptide from a tomato defensin exhibits antibacterial activities against Helicobacter pylori. J Pept Sci 18(12):755-762

65. Rodnin MV, Kyrychenko A, Kienker P, Sharma O, Vargas-Uribe M, Collier RJ Finkelstein A, Ladokhin AS (2011) Replacement of C-terminal histidines uncouples membrane insertion and translocation in diphtheria toxin Tdomain. Biophys J 101(10):L41-L43

66. Rodriguez-Palenzuela P, Pintor-Toro JA, Carbonero P, Garcia-Olmedo F (1988) Nucleotide sequence and endosperm-specific expression of the structural gene for the toxin alpha-hordothionin in barley (Hordeum vulgare L.). Gene 70(2):271-281

67. Sagaram US, Pandurangi R, Kaur J, Smith TJ, Shah DM (2011) Structureactivity determinants in antifungal plant defensins MsDef1 and MtDef4 with different modes of action against Fusarium graminearum. PLoS One 6(4): e18550

68. Samuelsson G, Pettersson B (1970) Separation of viscotoxins from the European mistletoe, Viscum album L. (Loranthaceae) by chromatography on sulfoethyl Sephadex. Acta Chem Scand 24(8):2751-2756

69. Samuelsson G, Pettersson B (1977) Toxic proteins from the mistletoe Dendrophtora clavata. II. The amino acid sequence of denclatoxin B. Acta Pharm Suec 14(3):245-254

70. Sathoff AE, Velivelli S, Shah DM, Samac DA (2019) Plant defensin peptides have antifungal and antibacterial activity against human and plant pathogens. Phytopathology 109(3):402-408

71. Sauviat MP, Berton J, Pater C (1985) Effect of phoratoxin B on electrical and mechanical activities of the rat papillary muscle. Zhongguo Yao Li Xue Bao 6(2):91-93

72. Schrader-Fischer G, Apel K (1993) cDNA-derived identification of novel thionin precursors in Viscum album that contain highly divergent thionin domains but conserved signal and acidic polypeptide domains. Plant Mol Biol 23(6):1233-1242

73. Schrader-Fischer G, Apel K (1994) Organ-specific expression of highly divergent thionin variants that are distinct from the seed-specific crambin in the crucifer Crambe abyssinica. Mol Gen Genet 245(3):380-389

74. Scocchi M, Mardirossian M, Runti G, Benincasa M (2016) Non-membrane permeabilizing modes of action of antimicrobial peptides on bacteria. Curr Top Med Chem 16(1):76-88

75. Selitrennikoff CP (2001) Antifungal proteins. Appl Environ Microbiol 67(7): 2883-2894

76. Shafee TM, Lay FT, Hulett MD, Anderson MA (2016) The defensins consist of two independent, convergent protein superfamilies. Mol Biol Evol 33(9): 2345-2356

77. Shai Y (1999) Mechanism of the binding, insertion and destabilization of phospholipid bilayer membranes by alpha-helical antimicrobial and cell nonselective membrane-lytic peptides. Biochim Biophys Acta 1462(1-2):55-70

78. Shigeri $Y$, Yasuda A, Hagihara $Y$, Nishi $K$, Watanabe $K$, Imura T, Inagaki $H$, Haramoto Y, Ito Y, Asashima M (2015) Identification of novel peptides from amphibian (Xenopus tropicalis) skin by direct tissue MALDI-MS analysis. Febs J 282(1):102-113

79. Spelbrink RG, Dilmac N, Allen A, Smith TJ, Shah DM, Hockerman GH (2004) Differential antifungal and calcium channel-blocking activity among structurally related plant defensins. Plant Physiol 135(4):2055-2067

80. Stec B (2006) Plant thionins--the structural perspective. Cell Mol Life Sci 63(12):1370-1385

81. Stec B, Markman O, Rao U, Heffron G, Henderson S, Vernon LP, Brumfeld V, Teeter MM (2004) Proposal for molecular mechanism of thionins deduced from physico-chemical studies of plant toxins. J Pept Res 64(6):210-224

82. Stec B, Rao U, Teeter MM (1995) Refinement of purothionins reveals solute particles important for lattice formation and toxicity. Part 2: structure of beta-purothionin at 1 . 7 A resolution. Acta Crystallogr D Biol Crystallogr 51(Pt 6):914-924

83. Stotz HU, Thomson JG, Wang Y (2009) Plant defensins: defense, development and application. Plant Signal Behav 4(11):1010-1012

84. Swathi Anuradha T, Divya K, Jami SK, Kirti PB (2008) Transgenic tobacco and peanut plants expressing a mustard defensin show resistance to fungal pathogens. Plant Cell Rep 27(11):1777-1786 
85. Tang D, Kang R, Coyne CB, Zeh HJ, Lotze MT (2012) PAMPs and DAMPs: signal 0 s that spur autophagy and immunity. Immunol Rev 249(1):158-175

86. Terras FR, Eggermont K, Kovaleva V, Raikhel NV, Osborn RW, Kester A, Rees SB, Torrekens S, Van Leuven F, Vanderleyden J et al (1995) Small cysteinerich antifungal proteins from radish: their role in host defense. Plant Cell 7(5):573-588

87. Thunberg E, Samuelsson G (1982) Isolation and properties of ligatoxin A, a toxic protein from the mistletoe Phoradendron liga. Acta Pharm Suec 19(4): 285-292

88. Underhill DM, Ozinsky A (2002) Toll-like receptors: key mediators of microbe detection. Curr Opin Immunol 14(1):103-110

89. van der Weerden NL, Lay FT, Anderson MA (2008) The plant defensin, NaD1, enters the cytoplasm of Fusarium oxysporum hyphae. J Biol Chem 283(21): $14445-14452$

90. Vriens K, Cammue BP, Thevissen K (2014) Antifungal plant defensins: mechanisms of action and production. Molecules 19(8):12280-12303

91. Wijaya R, Neumann GM, Condron R, Hughes AB, Polya GM (2000) Defense proteins from seed of Cassia fistula include a lipid transfer protein homologue and a protease inhibitory plant defensin. Plant Sci 159(2):243-255

92. Wong CT, Rowlands DK, Wong CH, Lo TW, Nguyen GK, Li HY, Tam JP (2012) Orally active peptidic bradykinin B1 receptor antagonists engineered from a cyclotide scaffold for inflammatory pain treatment. Angew Chem Int Ed Engl 51(23):5620-5624

93. Woriedh M, Merkl R, Dresselhaus T (2015) Maize EMBRYO SAC family peptides interact differentially with pollen tubes and fungal cells. J Exp Bot 66(17):5205-5216

94. Wu M, Maier E, Benz R, Hancock RE (1999) Mechanism of interaction of different classes of cationic antimicrobial peptides with planar bilayers and with the cytoplasmic membrane of Escherichia coli. Biochemistry 38(22): 7235-7242

95. Yamano A, Teeter MM (1994) Correlated disorder of the pure Pro22/Leu25 form of crambin at $150 \mathrm{~K}$ refined to 1.05-A resolution. J Biol Chem 269(19): 13956-13965

96. Yang L, Harroun TA, Weiss TM, Ding L, Huang HW (2001) Barrel-stave model or toroidal model? A case study on melittin pores. Biophys J 81(3):1475-1485

97. Yang X, Xia J, Yu Z, Hu Y, Li F, Meng H, Yang S, Liu J, Wang H (2012) Characterization of diverse antimicrobial peptides in skin secretions of Chungan torrent frog Amolops chunganensis. Peptides 38(1):41-53

98. Yount NY, Yeaman MR (2004) Multidimensional signatures in antimicrobial peptides. Proc Natl Acad Sci U S A 101(19):7363-7368

99. Zasloff M (2002) Antimicrobial peptides of multicellular organisms. Nature 415(6870):389-395

\section{Publisher's Note}

Springer Nature remains neutral with regard to jurisdictional claims in published maps and institutional affiliations.

\section{Submit your manuscript to a SpringerOpen ${ }^{\circ}$ journal and benefit from:}

- Convenient online submission

- Rigorous peer review

- Open access: articles freely available online

- High visibility within the field

- Retaining the copyright to your article

Submit your next manuscript at $\boldsymbol{\nabla}$ springeropen.com 